\title{
A violência escolar em matérias de jornal: Um imaginário construído em Belém-PA
}

Livia Sousa da Silva

Doutoranda em Ciências Sociais pela Universidade Federal do Pará. Bolsista do Conselho Nacional de Desenvolvimento Científico e Tecnológico (CNPQ).

E-mail: iviasilva@ufpa.br

Kátia Marly Leite Mendonça

Doutora em Ciência Política pela Universidade de São Paulo com Pós-Doutorado em Ética na Universidad Pontificia Comillas (Madrid/Espanha). Atualmente é professora associada da Universidade Federal do Pará.

E-mail: guadalupelourdes@hotmail.com

Resumo: Com a intenção de investigar a constituição do imaginário da violência escolar no texto midiático; por acreditar numa construção midiática perpassada de intencionalidades, que ao construir um imaginário para a violência escolar estará influenciando opiniões e decisões, quer seja no foro particular ou da esfera pública; participando mesmo da construção da violência escolar como objeto de estudo, de atenção e de intervenção; é que nos propomos neste trabalho a uma primeira incursão de investigação nessa arena de significações, conjugando estudos do campo da Sociologia da Comunicação e do Imaginário, e da Hermenêutica Compreensivo-Dialógica, para expor um prelúdio da tessitura de tal pesquisa.

Palavras-Chave: Violência Escolar; Mídia; Imaginário; Hermenêutica; Ética
Abstract: With the intention of investigating the constitution of the imaginary school violence in the media text; believing that the media is full of intentions that construct an imaginary of school violence influencing opinions and decisions, whether in the private or public sphere jurisdiction; participating even in the construction of school violence as an object of study, attention and intervention. That is what we propose in this work, a first incursion into this field of meanings, combining studies of Sociology of Communication and the Imaginary and studies of Comprehensive-Dialogical Hermeneutics, in order to expose a prelude to the framing of this research.

Keywords: School Violence; Media; Imaginary; Hermeneutics; Ethics 
comunicação \& educação • Ano XX • número 1 • jan/jun 2015

1. BACZKO, Bronislaw Les Imaginaires sociaux. Paris: Payot, 1994.

2. CASTORIADIS, C. A Instituição Imaginária da Sociedade. Rio de Janeiro: Paz e Terra, 1982.

3. DEBORD, Guy. A sociedade do espetáculo. São Paulo: Contraponto, 1997. VIRILIO, Paul. Cyberwar, God and Television: Interview with Paul Virilio. Entrevistador: Louise Wilson. Canada: Ctheory, 1994. Disponível em: <http://www.ctheory. net/articles.aspx?id=62> Acesso em: 25 fev. 2011

4. MENDONÇA, Kátia. Televisão: da profusão de imagens à cegueira ética. Revista FAMECOS, Porto Alegre, v. 20, n. 1, 2013. p. 179-192.

5. ABRAMOVAY, Miriam et al. Escola e violência. Brasília: UNESCO, 2002.

6. ABRAMOVAY, Miriam (2003). Enfrentando a Violência nas Escolas: Um Informe do Brasil. In: (Coord.). Violên-

cia na escola: América Latina e Caribe. Brasília: UNESCO, 2003.

7. LIMA, Regina Lúcia Alves de. Da pauta à veiculação das notícias, - posicionamento dos jornais paraenses nas eleições municipais de 2004 In: Amaral Filho, Otacílio; Castro-Horácio, Fábio Fonseca; Seixas, Netília Silva dos Anjos. (Org.). Pesquisa em Comunicação na Amazônia. Belém: FADESP, p. 101-113.

8. SILVA, Livia Sousa da. A midiatização da violência escolar: o cenário das produções acadêmicas. Ver a Educação, n. 1, 2011 , v. 12 , p. 159-182, jan./jun. Disponível em: http://www.peridicos. ufpa.br/index.php/rve/ article/view/1007/1463.

9. SILVA, 2011. Idem.

\section{INTRODUÇÃO}

A questão do imaginário social se mostra importante quando se trata da violência escolar, porque consideramos a hipótese de que o imaginário ${ }^{1}$ sendo ao mesmo tempo instituinte e instituído ${ }^{2}$ contém elementos que podem orientar ações sociais naquilo que, em uma sociedade do espetáculo ${ }^{3}$, poder-se-ia chamar de cegueira ética ${ }^{4}$ a incapacidade de percepção do outro e sua visada unicamente como objeto da violência. É sob esta perspectiva e hipótese que se constrói este artigo, tendo como elemento motivador o fato de a cidade de Belém do Pará ser uma das capitais mais violentas do Brasil e ao mesmo tempo possuir uma das mídias também ela mais violentas em termos imagéticos.

Fenômeno razoavelmente recente, a noticiação da violência escolar na mídia vem crescendo e tornando-se de conhecimento de toda a sociedade. Os poucos estudos realizados sobre violência escolar, sua divulgação lacônica e restrita, aliados às posturas negligentes de muitas escolas ${ }^{5}$ acabam por transferir à mídia, enquanto voz social, a responsabilidade pela divulgação das informações e casos sobre tal fenômeno. Essa última assume o papel de denunciadora participando da constituição da "violência escolar" enquanto problema social merecedor de atenção, estudo e intervenção ${ }^{6}$.

Pensar sobre os sentidos que a mídia produz sobre a violência escolar em Belém é também considerar que, para além de uma concepção ingênua de mídia, faz-se importante problematizá-la, já que ao propor as notícias como o faz, expressa, sobretudo, uma tomada de posição perante as questões sociais ${ }^{7}$. O que se configura em atitude cautelosa e justificável para uma melhor compreensão não só da violência escolar, mas, principalmente, do próprio funcionamento da mídia como articuladora de sentido e partícipe da construção da realidade social.

Os estudos de Silva ${ }^{8}$ acerca do cenário das produções no domínio da análise do discurso midiático sobre violência escolar, no entanto, demonstra que embora a mídia esteja construindo continuamente uma imagem sociocultural da escola, ao publicar a violência escolar em suas manchetes, as pesquisas continuam alheias à problematização de tais significações, destacando, dessa forma, o quanto o campo que se detém na pesquisa sobre a violência escolar é insipiente de estudos que possam traduzi-la numa compreensão de suas dimensões histórico-culturais.

Outro destaque dado por Silva ${ }^{9}$ está para a emergência de trabalhos que discutam as singularidades culturais e educacionais amazônidas em suas manifestações midiáticas, de maneira a se fazerem conhecer não só os processos de construção da opinião pública sobre certos fenômenos sociais, como a violência escolar, mas também para inseri-la de forma mais contundente no contexto maior das iniciativas de produção de conhecimento.

Assim, dentre um significativo conjunto de questões, ainda não investigadas, que afetam os processos educativos e, em especial, a escola na sociedade contemporânea, reiteramos a pertinência de um estudo que considere a mídia como partícipe da construção de certo imaginário da violência escolar 
na cidade de Belém e como vetor privilegiado dessas imagens. Levando em consideração que há um grande esforço para a compreensão do fenômeno da violência escolar, talvez seja tempo de considerar seus significados no âmbito da sua veiculação midiática.

\section{VIOLÊNCIA ESCOLAR E IMAGINÁRIO}

Abramovay $^{10}$ nos assevera que não há um significado único de violência ou pelo menos um que seja consensual, tratar-se-ia então de uma conceitualização ad hoc, ou seja, a mais apropriada ao lugar, ao tempo e aos atores que a examinam. Assim, várias atitudes e comportamentos passaram a ser considerados como formas de violência, ou seja, tomaram sentidos a partir das normas, das condições e dos contextos sociais, variando de um período histórico a outro passa-se a rotular de violentas formas de comportamento que, até então, eram vistas como tradicionais e ou que tinham ampla aceitação.

Por isso, acreditamos que a própria dificuldade de um consenso, mesmo entre pesquisadores do fenômeno da violência escolar, quanto a um conceito específico, estaria relacionada a sua dimensão imaginária intrínseca. Como a "atmosfera" constituída e constituinte de um povo, cada sociedade subsidiaria uma visão de violência escolar em congruência com seu próprio Imaginário Social, de onde todos os símbolos e imagens se articulam de maneira característica, como nos propõe Mafessoli ${ }^{11}$.

Não se trata para nós, como nos adverte Debarbieux e Blaya ${ }^{12}$, de encarar a violência escolar como "o que eu acho que ela seja", mas, do pressuposto de um acordo mais ou menos consensual de uma ideia de violência escolar que se assume como tal, contextualmente, numa sociedade, que lhe configuram e a conformam sob uma imagem partilhada, a que chamaremos Imaginário.

Seria a compreensão da violência escolar como Imaginário, que nos permitiria de uma maneira mais coerente, abordar os caminhos pelos quais os sentidos de "Violência Escolar" têm se constituído na mídia, para perceber seus reflexos nas ações de intervenção, e melhor entender seu papel social, considerando-a também como produtora de um ponto de vista sobre a violência escolar que dialoga com a sociedade de forma ampla.

Apoiamo-nos em Mafessoli ${ }^{13}$ para compreender o Imaginário como uma força social, que une e constrói uma imagem que funciona pela interação, uma certa sensação partilhada, e por isso, sempre coletivo. E poder ressaltar a importância do imaginário na construção da realidade e como o real é acionado pela eficácia do imaginário. No tocante à violência escolar, pensar em que medida um imaginário midiático traduz-se em ações e políticas de intervenção.

E, se o Imaginário forja-se na relação, pela comunicação e circulação de signos como nos sugere Mafessoli ${ }^{14}$, este não poderia deixar de considerar a mídia nesse processo, mas não pela perspectiva da manipulação e ou da imposição, e sim como relação. Pois, o indivíduo não está indefeso diante da imagem, “o criador, mesmo na publicidade, só é criador na medida em que consegue

10. ABRAMOVAY, 2002. Idem.

11. MAFFESOLI, Michel. Imaginaire et plurialité. Espirit Critique. 2, 2003, v. 2.

12. DEBARBIEUX, Éric; BLAYA, Catherine (orgs) Violência nas escolas: dez abordagens europeias. Brasília: UNESCO, 2002.

13. MAFESSOLI, Michel. O imaginário é uma realidade. Porto Alegre: entrevista concedida à Revista FAMECOS, $n^{\circ} 15$ 2001.

14. MAFESSOLI, 2001 Idem. 
comunicação \& educação • Ano XX • número 1 • jan/jun 2015

15. MAFESSOLI, 2001. Idem.

16. BARROS, F. A. F. A influência hermenêutica no atual referencial epistemológico da Sociologia. Revista Sociologias, n. 3, 2000. Disponíve em: <http://seer.ufrgs. br/sociologias/article/ view/7034>. Acesso em: 13 ago. 2014.

17. GADAMER, Hans-Georg. O problema da consciência histórica. 2. Ed. Rio de Janeiro: FGV, 2003 , p. 58.

18. RICOEUR, P. Do texto a ação. Ensaios de hermenêutica II. Porto: Rés, 1989.

19. RICOEUR, 1989. Idem.

20. BUBER, 1982. Idem; BUBER, Martim. Eu e Tu. São Paulo: Cortez \& Moraes, 2004. captar o que circula na sociedade [...] portanto as tecnologias do imaginário bebem em fontes imaginárias para alimentar imaginários"15.

\section{PROPOSIÇÕES HERMENÊUTICAS PARA A COMPREENŠ̃̃O DO TEXTO MIDIÁTICO}

Para Barros ${ }^{16}$ há uma grande influência da hermenêutica no atual referencial epistemológico da Sociologia, como uma nova feição epistemológica se introduzindo nas Ciências Sociais, o que acontece em decorrência de um longo processo histórico, no qual a influência da hermenêutica moderna tem se consubstanciado de maneira muito significativa que, ademais transformou a própria ciência em empreendimento compreensivo.

A Hermenêutica inicialmente esteve mais ligada à redução de objetos ao método científico, que se compunha de um conjunto de artifícios e de técnicas de explicação de textos, como um exercício de dissecação, que aos poucos vai se delineando para além do esforço metodológico/epistemológico ao ontológico; e desvencilhando-se de resquícios cientificistas para dar conta do que é humano, da compreensão não como instrumento, mas como constituinte humana que se manifesta pela linguagem e em relação a um "outro".

Assim, partilhamos da ideia de uma Hermenêutica muito mais como um processo de compreensão autenticamente histórica, pois que se desenvolve como um ato da existência, como nos propõe Gadamer. Desta forma, o texto seria a "manifestação de certo momento num processo de criação"17, sobre o qual se deva apreender o seu sentido - a perspectiva daquilo que nos é transmitido, ou seja, compreender seria participar de uma perspectiva comum. Assim, a Hermenêutica nos desponta para muito além de um método, e muito mais como uma atitude, uma consciência que é sempre receptiva e pensativa da realidade na sua historicidade.

Contudo, também não negligenciamos a atitude metodológica na seara científica e de produção de conhecimento no campo dos estudos nas Ciências Sociais, pois que consideramos a possível articulação entre Compreensão e Explicação, apoiados em Ricoeur ${ }^{18}$, de maneira a buscarmos um modelo onde se articulem uma ontologia da compreensão com a exigência crítica dos métodos rigorosos das ciências humanas. Cientes de que a compreensão pressupõe a participação intersubjetiva, pensamos semelhante à Ricoeur ${ }^{19}$ de que, deve-se articular compreensão e explicação ao nível do "sentido" da obra.

Refiro-me ainda mais profundamente, na credibilidade de uma Hermenêutica Dialógica, ao reportar-me a Buber $^{20}$ que ressalta o diálogo como um encontro aonde o traço fundamental seria a reciprocidade. De uma relação que se estabelece a partir do reconhecimento do outro como sujeito pleno, como voz a ser escutada e não reduzido a mero objeto de análise ou instrumentalização; pelo que Buber ${ }^{21}$ considera importante uma mudança de percepção das relações que estabelecemos entre o que ele denomina de EU-TU ou EU-ISSO. Buber (1982; 2004) ressalta ainda que o dialogismo não é próprio de qualquer 
forma de pensamento, independentemente da presença de um interlocutor. Da mesma forma que, também salienta, embora duas pessoas estando frente a frente falando uma com a outra, este momento não encerre um diálogo e tão somente um palavreado, porque só pode haver diálogo na relação EU-TU.

Disso já se depreende que, uma Hermenêutica Dialógica não poderia supor um texto como um objeto dissecável filológica e estruturalmente, na medida em que o reconhece como ato, onde se inscrevem posições, intenções e valorações do sujeito. Concordando com Buber diz Bakhtin, de maneira ainda mais direta que "a vida humana é um conjunto de atos cujo caráter ético é inescapável”"2. Desta forma, a dimensão ontológica torna-se mais uma vez inseparável do ato dialógico, já que segundo Buber ${ }^{23}$ é a propósito da relação EU-TU que nos tornamos humanos.

\section{PISTA PARA UM IMAGINÁRIO DA VIOLÊNCIA ESCOLAR NA CIDADE DE BELÉM-PA}

Silva e Alves ${ }^{24}$ nos dão pistas para uma compreensão do texto jornalístico, de maneira a considerar seu sentido a partir de uma relação dialógica, quando nos propõem a narrativa jornalística como composição entre um significado, que seria da ordem dos signos sempre reiteráveis na trama discursiva do jornal impresso que abordaram; um sentido assumido na enunciação concreta, ou seja, na relação enunciativa entre o jornal que fala, já pressupondo um interlocutor específico com quem estabelece diálogo, num certo contexto histórico, o que viria a conformar a própria tessitura jornalística; e por fim, um acento de valor, que se caracteriza pelo posicionamento ético assumido pelo discurso do jornal em relação ao fenômeno da violência escolar.

Embasados por esses elementos - significado, sentido e acento de valor que Silva e Alves ${ }^{25}$ desenvolvem todo seu empreendimento analítico do texto midiático, o qual estamos considerando como um bom exemplo de uma análise hermenêutica dialógica. Assim, observamos que na tessitura da trama discursiva dos jornais impresso O Liberal e Diário do Pará - os jornais de maior tiragem e acesso no estado do Pará - no período de 2011-2013 , certos elementos emergiam para além de seu significado dicionarizado, como signos ideológicos ${ }^{26}$, assumindo sentidos próprios das instâncias histórico-enunciativas em questão e por expressarem-se em termos valorativos.

Semelhante a alguns dos achados de Silva e Alves ${ }^{27}$, num comparativo da abordagem discursivo-dialógica de ambos os veículos, e embora representem no Estado posições políticas distintas e oposta, no tocante a abordagem discursiva do fenômeno da violência escolar, ambos a tratam a partir de determinações macroestruturais sobre o âmbito escolar, aonde o agressor externo - bandido, assaltante etc., seria o vetor de disseminação da violência no ambiente escolar, ou em vistas de "personalidades" violentas, aonde então figura a imagem do aluno tão somente como esse agente da violência em ambiente escolar. Em ambos os casos, a violência portaria uma raiz essencialmente exógena em relação à
21. BUBER, 1982. Idem; BUBER, 2004. Idem.

22. NUTO, João Vianney Cavalcanti. A influência de Martin Buber no conceito bakhtiniano de dialogismo. Revista Intercâmbio - UNB, 2010. Disponível em: <http:// unb.revistaintercambio. net.br/24h/conteudo/visualiza_lo03.php?pag=;revi staintercambio;paginas; $v$ isualiza_lo03\&cod=142>. Acesso em: 13 ago. 2014.

23. BUBER, 1982. Idem; BUBER, 2004. Idem.

24. SILVA, L. S.; ALVES, Laura Maria Silva Araújo. Uma análise bakhtiniana da verbo-visualidade da violência escolar em matérias de jornal. I Colóquio Internacional de mídia e discurso na Amazônia, Belém (PA), 2013.

25. SILVA E ALVES, 2013. Idem.

26. BAKHTIN, 2009. Idem. 27. SILVA E ALVES, 2013. Idem. 
prática institucional escolar, já que seria a violência urbana a formadora desses vetores de violência que, passam a reproduzi-la no ambiente interno escolar. Como se observa em alguns excertos dos veículos midiático:

[...] professor foi assaltado ontem à tarde, em Belém, dentro da Escola Estadual Vilhena Alves [...]. Ele teve o computador roubado por dois rapazes que usavam uniforme da escola. [...] Os jovens estavam armados e invadiram uma das salas de aula [...] acredita que os assaltantes tenham aproveitado o período de provas para roubar. (Fonte: Jornal Impresso O Liberal, 25/01/2013).

"As faces da violência escolar" [título da matéria] [...] membros de gangues infiltrados nos colégios [...] Os alunos roubam camisas de seus rivais de outras escolas e as exibem como troféu, [...] estudantes de escolas que possuem rivais em comum costumam combinar previamente os confrontos [...] A maioria briga e nem sabe porque está brigando. (Fonte: Jornal Impresso Diário do Pará, 02/06/2013).

"Trio tenta invadir escola na Pedreira" [título da matéria] Os criminosos foram encaminhados para a central de flagrantes [...] (Fonte: Jornal Impresso Diário do Pará, 10/05/2013).

Da mesma forma, evidenciamos em ambos os veículos midiáticos, o sobressalte dos bairros periféricos como geradores da violência que "adentra a escola", apontando-os por agrupamentos de pobres, que em virtude de suas condições socioeconômicas e vulnerabilidades de toda ordem, tornam-se violentos. Assim, tanto o "bandido" quanto o "aluno violento" não representariam a causa da violência, somente seus vetores, que seriam produto desse meio (o bairro) já violento. $\mathrm{O}$ que observamos em algumas passagens dos jornais pesquisados.

"O descaso é total. Por isso, já não tenho esperanças de que este quadro melhore. Olho para os lados e não encontro saída para esta situação”, declarou a educadora Marluce Colares, diretora da escola estadual Cidade de Emaús, localizada no bairro do Bengui, em Belém. O desabafo da diretora diz respeito à violência que ronda as dependências do estabelecimento de ensino. (Fonte: Jornal Impresso O Liberal, 21/09/2011).

A sociedade está violenta. Porque a escola não estaria? (Fonte: Jornal Impresso Diário do Pará, 08/04/2011).

Onda de violência em loteamento de Outeiro atinge a escola e moradores vizinhos (Fonte: Jornal Impresso Diário do Pará, 18/05/2013).

Para Bezerra ${ }^{28}$, essa associação entre camadas pobres e classes perigosas reforçadora da estigmatização das periferias das cidades, tem ganhado força no imaginário social no Brasil contemporâneo, vinculando pobreza-violência-criminalidade à desqualificação social do pobre que se torna a partir de então, potencialmente criminalizável em função do local de moradia. Esta imagem de espaços de insegurança, medo e periculosidade ganha visibilidade pública, denotando as hierarquias e distâncias sociais características de nossas sociedades. 
As situações de violência escolar expostas por esses veículos também apresentavam uma dupla posição mediante a figura do "aluno", que se constitui na oposição vítima/agressor. Assim, há estudantes que sofrem com a violência do ambiente escolar, e estes podem ser vítimas diretas, ou expectadores, testemunhas. E há aquele "aluno agressor" que dissemina a violência no ambiente escolar, que por suas ações descaracterizam o papel inicial da escola, que seria o da educação, que não reconhece mais a autoridade docente já que age em sua presença, dentro da sala de aula, sem qualquer respeito à sua figura e por fim inviabiliza o direito de todos à uma escola segura. É esse aluno, juntamente com o agressor externo (que muitas vezes confundem-se) são responsáveis pelo sentimento de insegurança na escola. Como observamos nos trechos destacados:

[...] e na frente de pelo menos outros 20 estudantes, além do professor, o adolescente esfaqueou o outro no peito e no pescoço. [...] O estudante agressor fugiu correndo da sala de aula [...] (Fonte: Jornal Impresso O Liberal, 20/04/2011).

[...] Chorei muito e fiquei desesperada, contou uma aluna adolescente que testemunhou a cena de violência e ficou traumatizada com o que viu [...] (Fonte: Jornal Impresso O Liberal, 20/04/2011).

Estudantes andam com medo da violência que impera entre alunos de escolas rivais. Eles marcam encontros na internet e se digladiam com paus e pedras em pleno dia (Fonte: Jornal Impresso Diário do Pará, 16/12/2013).

Toda a narrativa dos jornais vai nos apresentando o quanto compreende violência escolar como "coisa de aluno". Do aluno como um problema, ou "o problema" da escola, que precisa ser resolvido. Também se percebe insistentes indícios de criminalização desses alunos-agressores, que se revelam tanto por falas que o caracterizam como bandidos,

[...] A estudante contou que eles são envolvidos com drogas, pequenos furtos e o que chamou de "coisa errada"[...] (Fonte: Jornal Impresso O Liberal, 20/04/2011).

A crescente onda de violência entre adolescentes que tem assustado Belém, justamente no período em que deveriam estar no banco da escola recebendo ensinamentos, que contribuiriam para transformá-los em cidadãos íntegros[...] (Jornal Impresso Diário do Pará, 05/02/2012).

como pela maneira como se encaminham as providências da escola em relação ao caso: uma polícia especializada em aluno-agressor (Cipoe), encaminhamento ao sistema punitivo de adolescentes (DATA), registro de boletim de ocorrência em seccional - apenas medidas policialescas.

Segundo Sposito $^{29}$, as rondas e as vigílias dos estabelecimentos escolares e outros mecanismos de proteção ligados a distritos policiais efetivam-se desde a década de 1980. Resultado de compreensões do fenômeno da violência escolar e de suas formas de intervenção que parecem animar ainda hoje as inserções do discurso jornalístico acerca dessa questão, já que a ação policial é apontada como imprescindível na defesa da escola. 
29. SPOSITO, Marilia P. A Instituição Escolar e A Violência. Cadernos de Pesquisa (Fundação Carlos Chagas), São Paulo, v. 104, 2001, p. 58-75. Disponível em: <http://www. iea.usp.br/iea/textos/>. Acesso em: 18 fev. 2011.

30. MORAIS, J. F. S. A escola pública e os discursos sobre sua pretensa crise. Teias: Rio de Janeiro, ano 2, n. 4. 2001. spositoescolaeviolencia.pdf.
"PM acaba guerra entre alunos" [título da matéria] Policiais detiveram três envolvidos em duas 'batalhas' entre alunos [...] (lead). (Fonte: Jornal Impresso $O$ Liberal, 16/06/2012).

A direção da escola acionou a Companhia Independente de Policiamento Escolar (Cipoe), que monitorou a situação. (Fonte: Jornal Impresso Diário do Pará, 25/01/2013).

A proposição do descrédito da escola pública também é bastante marcante, na abordagem da violência escolar de O Liberal e Diário do Pará, por lhe atribuir sentidos que mais a ressaltam por seus problemas, sua inoperância e incompetência, atribuindo-lhe um valor de desqualificação, e questionando-se a escola no seu papel social.

Nas escolas públicas vemos que o tráfico de drogas, o bullying, as brigas e formação de gangues são mais constantes. Nas particulares isso diminui. (Fonte: Jornal Impresso O Liberal, 20/04/2011).

Por apresentar menor Índice de Desenvolvimento de Educação, escola estadual Cidade de Emaús, foi mostrada no Jornal Nacional, da Rede Globo. (Fonte: Jornal Impresso O Liberal, 21/09/2011).

"Escola não é mais espaço seguro". As pessoas pensam que a escola é um lugar sagrado, de respeito. Essa é uma visão tradicionalista, e agora acontece essa dessacralização do ambiente escolar [...]" (Fonte: Jornal Impresso Diário do Pará, 08/04/2011).

Morais $^{30}$ nos ajuda a refletir sobre tais asserções, uma vez que considera histórico o movimento discursivo que objetiva apontar a escola brasileira como um palco de crises. Um esquema argumentativo que busca nos convencer de que a gerência estatal transformou o sistema escolar num espaço sofrível, marcado pela desigualdade, incompetência e ineficácia. O que tem concorrido para a depreciação e desmerecimento do caráter público da escola, representando-a por um modelo fracassado. Iniciativas que, segundo tal autora, sugerem a retirada da esfera pública, substituindo-a pela esfera privada, para a superação da crise em que a escola pública se encontraria.

Outro indicativo interessante na abordagem discursiva de $O$ Liberal e Diário do Pará está para a insistente presença do professor apenas como vítima das ações violentas, e nunca como autor. O que Silva e Alves ${ }^{31}$ tratam como uma visão "tradicional" do professor, manifesta sob um papel social legítimo mesmo se arbitrário, reportando-se às tradicionais configurações escolares e práticas docentes, sugerindo o valor e a importância do professor acima dos demais constituintes escolares sobretudo os alunos. Assim, relaciona-se a violência contra o professor como consequência da perda da autoridade docente, que o fragiliza e o torna vítima e/ou testemunha mediante as condições de violência existentes na escola. 
"Professor sofre assalto dentro da sala de aula" [título da matéria] "A gente vem trabalhar, deixa a família em casa e não sabe se volta porque aqui na porta a gente é assaltado, dentro da escola a gente é assaltado. É complicado." (Fonte: Jornal Impresso O Liberal, 26/01/2013).

A violência é de aluno para aluno e aluno para professor, que também sofre ameaças. (Fonte: Jornal Impresso Diário do Pará, 07/04/11).

Assim concluímos nossas inserções no campo da compreensão do texto midiático, com a clareza de que, embora muito preliminarmente, nossa incursão nos consubstancia não só de elementos importantes para a compreensão da violência escolar como construto imaginário na cidade de Belém-PA, ao destacar que, a abordagem midiática da violência escolar de O Liberal e Diário do Pará, orienta para uma conformação de compreensão do fenômeno pelas vias da culpa centrada no sujeito (aluno), e pelo desmerecimento da escola pública como instituição de ensino e de educação de qualidade; ou seja, como coisa de escola pública, de aluno pobre e de bairro periférico. Como nos orienta, a partir do que chamamos de "algumas pistas", em virtude de seu arcabouço epistemológico, para a realização de uma análise hermenêutico-dialógica das narrativas jornalísticas.

\section{CONSIDERAÇÕES FINAIS}

Entendemos que ao estudar um fenômeno complexo como o é a violência escolar, precisamos conjugar esforços para uma compreensão para além do esboço linear e des-historicizado e atemporal proposto tanto pelo senso comum, como até mesmo por algumas iniciativas de pesquisa; em virtude de uma abordagem epistemológica que o ressalte em suas configurações mais subterrâneas, ao sobrelevar-lhe o âmago responsável por toda ação empreendida no âmbito da escola em relação à violência, que só poderia transparecer pelo reconhecimento da violência escolar, antes de tudo, como um Imaginário Social.

Isso nos situa novamente no papel ético e responsável da intersubjetividade narrativa que circula toda a sociedade através das imagens veiculadas na mídia, mas constituídas por todos nós, agentes sociais, que partilhamos esses sentidos, valorizando-os, enaltecendo-os e os consumindo, não como sujeitos indefesos e alienados, mas como participes de tramas discursivas, de tessituras narrativas, de painéis imagéticos que ainda insistimos em cultivar; o que só uma hermenêutica de fundo compreensivo-dialógico nos possibilitaria refletir

Negligenciando ainda como sociedade, as muitas especificidades dos contextos escolares amazônidas que se desvanecem nessa partilha de sentido acerca da violência escolar; que poderia estar valorizando mais o potencial dos alunos para o resgate da importância e valor da escola pública junto a essa sociedade e encarando seus problemas mais enraizados e pouco discutidos como o é o caso da imposição disciplinar, das relações expressamente verticalizadas, que inviabilizam o diálogo, o respeito mútuo, e até mesmo, uma cultura de não-violência.

31. SILVA E ALVES, 2013. Idem. 
comunicação \& educação • Ano XX • número 1 • jan/jun 2015

\section{REFERÊNCIAS}

ABRAMOVAY, Miriam (2003). Enfrentando a Violência nas Escolas: Um Informe do Brasil. In: (Coord.). Violência na escola: América Latina e Caribe. Brasília: UNESCO, 2003.

ABRAMOVAY, Miriam et al. Escola e violência. Brasília: UNESCO, 2002.

BACZKO, Bronislaw. Les Imaginaires sociaux. Paris: Payot, 1994.

BARROS, F. A. F. A influência hermenêutica no atual referencial epistemológico da Sociologia. Revista Sociologias, n. 3, 2000. Disponível em: $<$ http://seer.ufrgs.br/sociologias/article/view/7034>.

BEZERRA, L. M. P. S. Sentidos da pobreza e do viver em territórios estigmatizados. V Jornada Internacional de Políticas Públicas, 2011.

BUBER, 1982. Idem; BUBER, Martim. Eu e Tu. São Paulo: Cortez \& Moraes, 2004. CASTORIADIS, G. A Instituição Imaginária da Sociedade. Rio de Janeiro: Paz e Terra, 1982.

DEBARBIEUX, Éric; BLAYA, Catherine (orgs). Violência nas escolas: dez abordagens europeias. Brasília: UNESCO, 2002.

DEBORD, Guy. A sociedade do espetáculo. Contraponto, São Paulo, 1997. VIRILIO, Paul. Cyberwar, God and Television: Interview with Paul Virilio. Entrevistador: Louise Wilson. Canada: Ctheory, 1994. Disponível em: <http:/ / www.ctheory.net/articles.aspx?id=62>. Acesso em: 25 fev. 2011.

GADAMER, Hans-Georg. O problema da consciência histórica. 2. ed. Rio de Janeiro: FGV, 2003.

LIMA, Regina Lúcia Alves de. Da pauta à veiculação das notícias, o posicionamento dos jornais paraenses nas eleições municipais de 2004. In: Amaral Filho, Otacílio; Castro-Horácio, Fábio Fonseca; Seixas, Netília Silva dos Anjos. (Org.). Pesquisa em Comunicação na Amazônia. Belém(PA): FADESP, p. 101-113.

MAFESSOLI, Michel. O imaginário é uma realidade. Porto Alegre: entrevista concedida à Revista FAMECOS, $n^{\circ}$ 15, 2001.

Imaginaire et plurialité. Espirit Critique. 2, 2003, v. 5.

MENDONÇA, Kátia. Televisão: da profusão de imagens à cegueira ética. Revista FAMECOS, Porto Alegre, n. 1, 2013, v. 20, p. 179-192.

MORAIS, J. F. S. A escola pública e os discursos sobre sua pretensa crise. Teias, Rio de Janeiro, ano 2, n. 4. 2001.

NUTO, João Vianney Cavalcanti. A influência de Martin Buber no conceito bakhtiniano de dialogismo. Revista Intercâmbio - UNB, 2010. Disponível em: $<$ http://unb.revistaintercambio.net.br/24h/conteudo/visualiza_lo03.php?pag=;rev istaintercambio;paginas;visualiza_lo03\&cod=142>. Acesso em: 13 ago. 2014. 
RICOEUR, P. Do texto a ação. Ensaios de hermenêutica II. Porto: Rés, 1989.

SILVA, L. S.; ALVES, Laura Maria Silva Araújo. Uma análise bakhtiniana da verbo-visualidade da violência escolar em matérias de jornal. I Colóquio Internacional de mídia e discurso na Amazônia, Belém (PA), 2013.

SILVA, Livia Sousa da. A midiatização da violência escolar: o cenário das produções acadêmicas. Ver a Educação, n. 1, 2011, v. 12, p. 159-182, jan. /Jun. Disponível em: <http://www.periodicos.ufpa.br/index.php/rve/article/ view $/ 1007 / 1463>$.

SPOSITO, Marilia P. A Instituição Escolar e A Violência. Cadernos de Pesquisa (Fundação Carlos Chagas), São Paulo, 2001, v. 104, p. 58-75. Disponível em: <http://www.iea.usp.br/iea/textos/spositoescolaeviolencia.pdf >. Acesso em: 18 fev. 2011. 